\title{
Efficacy of pulmonary surfactant combined with high-dose ambroxol hydrochloride in the treatment of neonatal respiratory distress syndrome
}

\author{
JIAJUN XIANG $^{1}$ and PING WANG ${ }^{2}$ \\ Departments of ${ }^{1}$ Paediatrics and ${ }^{2}$ Operation, Linyi Central Hospital, Linyi, Shandong 276400, P.R. China
}

Received December 4, 2018; Accepted April 24, 2019

DOI: $10.3892 /$ etm.2019.7615

\begin{abstract}
Clinical efficacy of pulmonary surfactant combined with high-dose ambroxol hydrochloride in the treatment of neonatal respiratory distress syndrome (NRDS) was investigated. One hundred child patients with NRDS in Linyi Central Hospital were collected according to the diagnostic criteria for RDS in the Pediatrics, and randomly divided into the treatment group $(n=50)$ and the control group $(n=50)$ based on different therapeutic methods. Patients in the control group were treated with basic treatment and high-dose ambroxol hydrochloride injection, while those in the treatment group were additionally administered with pulmonary surfactant Curosurf based on conventional therapy in the control group. The chest X-rays were collected before the treatment and at $12 \mathrm{~h}$ after the drug administration, the degree of respiratory distress in child patients was observed and evaluated via Silverman grading, and changes in blood gas indexes were recorded before treatment and at 2, 6 and $12 \mathrm{~h}$ after the drug administration. The chest X-ray grade, Silverman grade and blood gas analysis results had no differences between the two groups before the treatment $(\mathrm{P}>0.05)$. In the treatment group, partial pressure of oxygen $\left(\mathrm{PaO}_{2}\right)$ and $\mathrm{PH}$ were increased and partial pressure of carbon dioxide $\left(\mathrm{PaCO}_{2}\right)$ was decreased compared with those in the control group at 2, 6 and $12 \mathrm{~h}$ after the drug administration $(\mathrm{P}<0.05)$. At $12 \mathrm{~h}$ after the drug administration, chest X-ray grade and Silverman grade in both groups were improved, which were significantly superior in the treatment group to those in the control group $(\mathrm{P}<0.01)$. Moreover, the efficacy in the treatment group was remarkably better than that in the control group at $12 \mathrm{~h}$ after drug administration $(\mathrm{P}<0.01)$. Pulmonary surfactant combined with high-dose ambroxol hydrochloride has definite efficacy in the treatment of NRDS, which can significantly improve the pulmonary infection, respiratory distress and blood gas indexes of child patients.
\end{abstract}

Correspondence to: Dr Jiajun Xiang, Department of Paediatrics, Linyi Central Hospital, 17 Jiankang Road, Linyi, Shandong 276400, P.R. China

E-mail: fvh5tcb@163.com

Key words: neonatal respiratory distress syndrome, pulmonary surfactant, ambroxol hydrochloride

\section{Introduction}

Neonatal respiratory distress syndrome (NRDS) refers to dyspnea symptoms such as cyanosis, tachypnea, expiratory sigh, nasal ala flap and inspiratory three-concave sign due to the lack of pulmonary surfactant in neonates after birth, which can lead to death of child patients in severe cases (1). According to the epidemiological survey, the incidence rate of NRDS is up to $7.8 \%$ with a fatality rate of $50 \%$ in premature infants (2), which is easy to cause chronic lung disease in children and affects the life safety and healthy growth of children. Mechanical ventilation is the most commonly used treatment method for NRDS, but it is easy to cause complications such as barotrauma and tracheo-pulmonary dysplasia in children with alveolar collapse. There are many causes of the disease, mainly due to the insufficient secretion of pulmonary surfactant. Therefore, the key to treatment is to supplement the pulmonary surfactant or promote the generation of pulmonary surfactant. In clinical conventional therapy, ambroxol is often used to stimulate alveolar cells to secrete pulmonary surfactant, but its effect is still not obvious.

In the present study, therefore, pulmonary surfactant combined with high-dose ambroxol hydrochloride was applied in the treatment of NRDS, and its clinical efficacy was explored.

\section{Patients and methods}

Study subjects. A total of 100 child patients with neonatal respiratory distress syndrome (NRDS) treated in the Linyi Central Hospital (Linyi, China) from March 2016 to December 2017, were selected as subjects of study according to the diagnostic criteria for RDS in the Pediatrics. Inclusion criteria were: i) child patients meeting the diagnostic criteria for RDS in Pediatrics; ii) child patients whose families were informed and willing to cooperate in the study; and iii) child patients without a history of obstetrical diseases, such as premature rupture of membrane and amniotic fluid pollution. Exclusion criteria were: i) child patients with severe hypoxemia before treatment; ii) child patients who were allergic to pulmonary surfactant or ambroxol hydrochloride; or iii) child patients diagnosed with lung diseases, such as pneumonia or wet lung disease. 
Table I. Comparison of general clinical data.

\begin{tabular}{lcccc}
\hline Group & Male/female & Gestational age (weeks) & Birth weight (g) & Day age (days) \\
\hline Control group & $28 / 22$ & $34.25 \pm 2.12$ & $2272.00 \pm 540.40$ & $4.21 \pm 1.41$ \\
Treatment group & $26 / 24$ & $34.36 \pm 2.24$ & $2235.00 \pm 535.47$ & $4.17 \pm 1.42$ \\
$\chi^{2} / \mathrm{t}$ & 0.161 & 0.140 & 0.423 & 0.212 \\
P-value & 0.688 & 0.701 & 1.212 & 0.981 \\
\hline
\end{tabular}

Table II. Comparison of chest X-ray grade before treatment.

\begin{tabular}{|c|c|c|c|c|c|c|}
\hline \multirow[b]{2}{*}{ Group } & \multirow[b]{2}{*}{$\mathrm{n}$} & \multicolumn{3}{|c|}{ Chest X-ray grade } & \multirow[b]{2}{*}{$\chi^{2}$} & \multirow[b]{2}{*}{ P-value } \\
\hline & & Grade I & Grade II & Grade III & & \\
\hline Control group & 50 & $15(30.00)$ & $27(54.00)$ & $8(16.00)$ & & \\
\hline Treatment group & 50 & $11(22.00)$ & $27(54.00)$ & $12(24.00)$ & 1.415 & 0.493 \\
\hline
\end{tabular}

The 100 child patients with NRDS were randomly divided into the treatment $(n=50)$ and control $(n=50)$ groups using Statistical Product and Service Solutions (SPSS) 20.0 software. In the treatment group, there were 26 male and 24 female patients with an average gestational age of $34.36 \pm 2.24$ weeks and an average age of $4.17 \pm 1.42$ days. In the control group, there were 28 male and 22 female patients with an average gestational age of $34.25 \pm 2.12$ weeks and an average age of 4.21 1.41 days.

Families of child patients in the two groups signed informed consent. The study was approved by the Ethics Committee of Linyi Central Hospital.

Treatment methods. Child patients in the two groups were kept warm in an incubator and given continuous positive airway pressure and nutritional support via fluid infusion. Patients in the control group were treated with intravenous injection of high-dose ambroxol hydrochloride injection (Boehringer Ingelheim Espana, S.A., Barcelona, Spain; NMPN H20130779) (30 mg/kg, 2 times/day) for 3 consecutive days. Patients in the treatment group were treated additionally with intratracheal drip of pulmonary surfactant Curosurf (poractant alfa injection; Chiesi Farmaceutici S.p.A., Parma, Italy; NMPN H20080429) $(100-200 \mathrm{mg} / \mathrm{kg}$ ) based on the conventional therapy in control group, and Curosurf could be applied additionally $(100 \mathrm{mg} / \mathrm{kg})$ after $12 \mathrm{~h}$ when necessary.

Observation indexes. According to the scoring criteria of chest X-ray diagnostics, the chest X-ray grade was observed before treatment and at $12 \mathrm{~h}$ after drug administration to evaluate the pulmonary conditions. The severity of NRDS was assessed according to the Silverman scoring criteria (3), and the superior thoracic, inferior thoracic and subcostal depression, nasal ala flap, expiratory sigh and other symptoms were observed in the two groups during the treatment. Changes in blood gas indexes were recorded before treatment and at 2, 6 and $12 \mathrm{~h}$ after drug administration, and whether adverse reactions occurred during the treatment was observed.
Efficacy evaluation. Effective: after treatment, the clinical symptoms of child patients disappeared or were alleviated, the X-ray displayed that the abnormal shadow area in the lung had disappeared or was improved, and the blood gas indexes were normal or improved. Ineffective: after treatment, the clinical symptoms of child patients were aggravated or not improved, the X-ray displayed that the shadow area had expanded or not improved, and the blood gas indexes were worsen or not improved.

Statistical analysis. The SPSS 20.0 statistical analysis software (IBM Corp., Armonk, NY, USA) was used for data processing. Measurement data were expressed as mean $\pm \mathrm{SD}$. The independent-samples t-test was used for the comparison of measurement data meeting normal distribution between the two groups, and the Chi-square test was used for the comparison of measurement data and enumeration data meeting abnormal distribution. ANOVA and LSD post hoc test was used for comparison between multiple groups. $\mathrm{P}<0.05$ indicates that the difference was statistically significant.

\section{Results}

Comparison of general data. There were no differences in the general clinical data between the two groups of child patients $(\mathrm{P}>0.05)$ (Table I).

Comparison of chest $X$-ray grade before treatment. The chest $\mathrm{X}$-ray grade had no difference between the two groups of child patients before treatment $(\mathrm{P}>0.05)$ (Table II).

Comparison of Silverman grade before the treatment. The Silverman grade had no difference between the two groups of child patients before treatment $(\mathrm{P}>0.05)$ (Table III).

Comparison of changes in blood gas indexes before and after treatment. There were no differences in blood gas indexes between the two groups before treatment $(P>0.05)$. In the 
Table III. Comparison of Silverman grade before treatment.

\begin{tabular}{lrrrrrr}
\hline & & \multicolumn{3}{c}{ Silverman grade } \\
\cline { 3 - 5 } Group & $\mathrm{n}$ & Grade I & Grade II & Grade III & $\chi^{2}$ & P-value \\
\hline Control group & 50 & $13(26.00)$ & $21(42.00)$ & $16(32.00)$ & & \\
Treatment group & 50 & $9(18.00)$ & $21(42.00)$ & $20(40.00)$ & 1.172 & 0.557 \\
\hline
\end{tabular}

Table IV. Comparison of changes in blood gas indexes before and after treatment.

\begin{tabular}{llcrrr}
\hline Group & Index & Before treatment & $\begin{array}{c}2 \mathrm{~h} \text { after drug } \\
\text { administration }\end{array}$ & $\begin{array}{c}6 \mathrm{~h} \text { after drug } \\
\text { administration }\end{array}$ & $\begin{array}{r}12 \mathrm{~h} \text { after drug } \\
\text { administration }\end{array}$ \\
\hline Control group & $\mathrm{PaO}_{2}$ & $44.32 \pm 6.37$ & $49.38 \pm 6.04$ & $58.87 \pm 5.79$ & $66.39 \pm 5.47$ \\
& $\mathrm{PaCO}_{2}$ & $43.92 \pm 6.48$ & $41.98 \pm 6.36$ & $38.93 \pm 5.87$ & $35.41 \pm 5.47$ \\
& $\mathrm{pH}$ & $7.17 \pm 0.05$ & $7.19 \pm 0.06$ & $7.22 \pm 0.05$ & $7.31 \pm 0.02$ \\
Treatment group & $\mathrm{PaO}_{2}$ & $43.25 \pm 5.92$ & $53.48 \pm 5.38^{\mathrm{a}}$ & $69.68 \pm 5.10^{\mathrm{a}}$ & $89.49 \pm 4.71^{\mathrm{a}}$ \\
& $\mathrm{PaCO}_{2}$ & $45.36 \pm 6.13$ & $40.40 \pm 5.41^{\mathrm{b}}$ & $34.69 \pm 4.89^{\mathrm{b}}$ & $29.12 \pm 4.59^{\mathrm{b}}$ \\
& $\mathrm{pH}$ & $7.16 \pm 0.06$ & $7.21 \pm 0.05^{\mathrm{c}}$ & $7.23 \pm 0.04^{\mathrm{c}}$ & $7.32 \pm 0.03^{\mathrm{c}}$ \\
\hline
\end{tabular}

${ }^{\mathrm{a}}<0.05$ vs. $\mathrm{PaO}_{2}$ in the control group, ${ }^{\mathrm{b}} \mathrm{P}<0.05$ vs. $\mathrm{PaCO}_{2}$ in the control group, and ${ }^{\mathrm{c}} \mathrm{P}<0.05$ vs. $\mathrm{PH}$ in the control group.

Table V. Comparison of chest X-ray grade at $12 \mathrm{~h}$ after drug administration.

\begin{tabular}{lcccccr}
\hline & & \multicolumn{3}{c}{ Chest X-ray grade } & & \\
\cline { 3 - 5 } Group & $\mathrm{n}$ & Grade I & Grade II & Grade III & $\chi^{2}$ & P-value \\
\hline Control group & $20 / 50$ & $13 / 15$ & $5 / 27$ & $2 / 8$ & & 0.008 \\
Treatment group & $44 / 50$ & $11 / 11$ & $27 / 27$ & $6 / 12$ & 9.648 & \\
\hline
\end{tabular}

Table VI. Comparison of Silverman grade at $12 \mathrm{~h}$ after drug administration.

\begin{tabular}{lccccrr}
\hline & & \multicolumn{3}{c}{ Silverman grade } & & \\
\cline { 3 - 7 } Group & $\mathrm{n}$ & Grade I & Grade II & Grade III & $\chi^{2}$ & P-value \\
\hline Control group & $20 / 50$ & $11 / 13$ & $6 / 21$ & $3 / 16$ & & \\
Treatment group & $44 / 50$ & $9 / 9$ & $21 / 21$ & $14 / 20$ & 7.739 & 0.021 \\
\hline
\end{tabular}

treatment group, partial pressure of oxygen $\left(\mathrm{PaO}_{2}\right)$ and $\mathrm{pH}$ were increased and partial pressure of carbon dioxide $\left(\mathrm{PaCO}_{2}\right)$ was decreased compared with those in the control group at 2, 6 and $12 \mathrm{~h}$ after drug administration $(\mathrm{P}<0.05)$ (Table IV).

Comparison of chest $X$-ray grade at $12 \mathrm{~h}$ after drug administration. At $12 \mathrm{~h}$ after drug administration, the chest X-ray grade in both groups was improved, which was significantly superior in the treatment group to that in the control group $(\mathrm{P}<0.01)($ Table V).

Comparison of Silverman grade at $12 \mathrm{~h}$ after drug administration. At $12 \mathrm{~h}$ after drug administration, the Silverman grade in the two groups was improved, and the degree of NRDS was
Table VII. Comparison of efficacy after treatment (\%).

\begin{tabular}{lrrrr}
\hline Group & Effective & Ineffective & $\chi^{2}$ & P-value \\
\hline Control group & $20(40.00)$ & $30(60.00)$ & & \\
Treatment group & $44(88.00)$ & $6(12.00)$ & 25.000 & $<0.01$
\end{tabular}

alleviated, which was superior in the treatment group to that in the control group $(\mathrm{P}<0.01)$ (Table VI).

Comparison of efficacy. The efficacy $(88.00 \%)$ in the treatment group was remarkably better than that $(40.00 \%)$ in the control group at $12 \mathrm{~h}$ after drug administration $(\mathrm{P}<0.01)$ (Table VII). 


\section{Discussion}

Neonatal respiratory distress syndrome (NRDS) mainly refers to relevant symptoms such as progressive dyspnea and respiratory failure in neonates shortly after birth. The pathogenesis of NRDS is complex, which, according to studies, may be related to premature delivery, cesarean section, genetic variation and maternal diabetes $(4,5)$. The basic pathogenesis of NRDS is acute diffuse alveolar capillary injury, leading to increased pulmonary capillary permeability and alveolar and pulmonary interstitial edema, ultimately resulting in damage to type II alveolar cells. Such damage reduces the pulmonary surfactant, so that the alveolar surface tension declines, the alveolar group shrinks, and the pulmonary ventilation/blood flow ratio becomes abnormal, eventually causing severe hypoxemia (6-8). NRDS is a key cause of death of neonates and premature infants $(9,10)$, thus, it is of great importance to develop scientific and reasonable therapeutic regimen timely and effectively.

NRDS is mainly caused by the lack of pulmonary surfactant, thus, its treatment should aim at the pulmonary surfactant. According to related current reports, the pulmonary surfactant can improve the pulmonary respiratory function and pulmonary compliance, and increase the oxyhemoglobin saturation in NRDS, thereby reducing the mechanical ventilation time of child patients $(11,12)$. The pulmonary surfactant is a kind of mixture composed of specific protein and phospholipid and mainly secreted by type II alveolar cells, which reduces the alveolar surface tension and prevents alveolar atrophy. Curosurf is a natural pulmonary surfactant extracted from the pig lung, which is composed of $41-48 \%$ lecithin and $51-58 \%$ other phospholipids and hydrophobin. After Curosurf enters the airway, it is absorbed by the liquid-gel layer, so bucking and other discomfort do not occur easily, the pulmonary compliance and pulmonary oxygen saturation can be increased, and the pulmonary capacity and functional residual capacity can be improved, thus, promoting the pulmonary respiratory function (13). Curosurf treatment seldom causes bucking and other discomfort in child patients, with rapid onset and long-term action, which, according to the research of some scholars, has an excellent therapeutic effect on NRDS $(14,15)$. Ambroxol hydrochloride, also known as ambrotherxol hydrochloride, is a kind of mucolytic and an active metabolite of bromhexine in the body, which can specifically bind to lung tissues, stimulate the phospholipid synthesis, reduce the generation of hydrogen peroxide and superoxide anion, promote the generation and secretion of pulmonary surfactant, reduce lung damage, alleviate the inflammatory response, attenuate alveolar epithelial cell damage, relieve pulmonary edema and decrease pulmonary interstitial exudation. Ambroxol hydrochloride is characterized by convenient application, low cost and high safety, so it has been used as a conventional drug in the clinical treatment of NRDS (16-19).

In the present study, pulmonary function was observed in both groups after additional application of pulmonary surfactant in the treatment group, and results revealed that the symptoms in both groups were improved after treatment, but the therapeutic effect in the treatment group was more obvious. Blood gas indexes were analyzed at 2, 6 and $12 \mathrm{~h}$ after treatment, and it was found that the chest X-ray grade and Silverman grade were improved, which were superior in the treatment group to those in the control group, indicating that under the heat preservation, basic nutritional support and continuous positive airway pressure, the high-dose ambroxol hydrochloride and pulmonary surfactant are able to improve the NRDS symptoms, such as blood gas, pulmonary infection and respiratory distress, and the application of pulmonary surfactant based on high-dose ambroxol hydrochloride has a definite efficacy, which are consistent with research conclusions of other scholars $(20,21)$. Therefore, it is recommended that the pulmonary surfactant combined with high-dose ambroxol hydrochloride be applied based on the basic treatment in the clinical treatment of NRDS.

\section{Acknowledgements}

Not applicable.

\section{Funding}

No funding was received.

\section{Availability of data and materials}

The datasets used and/or analyzed during the current study are available from the corresponding author on reasonable request.

\section{Authors' contributions}

JX wrote the manuscript. JX and PW were responsible for the observation indexes analysis. PW collected and analyzed the general data of the patients. Both authors read and approved the final manuscript.

\section{Ethics approval and consent to participate}

The study was approved by the Ethics Committee of Linyi Central Hospital (Linyi, China) and written informed consents were signed by the parents of the child patients.

\section{Patient consent for publication}

Not applicable.

\section{Competing interests}

The authors declare that they have no competing interests.

\section{References}

1. Sweet D, Carnielli V, Greisen G, Hallman M, Ozek E, Plavka R, Saugstad OD, Simeoni U, Speer CP and Halliday HL; European Association of Perinatal Medicine: European consensus guidelines on the management of neonatal respiratory distress syndrome in preterm infants--2013 update. Zhonghua Er Ke Za Zhi 52: 749-755, 2014 (In Chinese).

2. Zhou B, Zhai JF, Wu JB, Jin B and Zhang YY: Different ventilation modes combined with ambroxol in the treatment of respiratory distress syndrome in premature infants. Exp Ther Med 13: 629-633, 2017.

3. Rodriguez RJ: Management of respiratory distress syndrome: An update. Respir Care 48: 279-286, discussion 286-287, 2003. 
4. Liszewski MC, Stanescu AL, Phillips GS and Lee EY: Respiratory distress in neonates: Underlying causes and current imaging assessment. Radiol Clin North Am 55: 629-644, 2017.

5. Tochie JN, Choukem SP, Langmia RN, Barla E and KokiNdombo P: Neonatal respiratory distress in a reference neonatal unit in Cameroon: An analysis of prevalence, predictors, etiologies and outcomes. Pan Afr Med J 24: 152, 2016.

6. Tabit CE, Chung WB, Hamburg NM and Vita JA: Endothelial dysfunction in diabetes mellitus: Molecular mechanisms and clinical implications. Rev Endocr Metab Disord 11: 61-74, 2010.

7. Jobe AH: Lung maturational agents and surfactant treatments: Are they complementary in preterm infants? J Perinatol 9: 14-18 1989.

8. Speer CP: Neonatal respiratory distress syndrome: An inflammatory disease? Neonatology 99: 316-319, 2011.

9. Rijal P and Shrestha M: Scenario of neonatal respiratory distress in tertiary hospital. J Nepal Health Res Counc 16: 131-135, 2018

10. Gitaka J, Natecho A, Mwambeo HM, Gatungu DM, Githanga D and Abuya T: Evaluating quality neonatal care, call centre service, tele-health and community engagement in reducing newborn morbidity and mortality in Bungoma county, Kenya. BMC Health Serv Res 18: 493, 2018.

11. Fan YZ and Wen ZL: Efficacy of different dosages of ambroxol hydrochloride in the prevention of neonatal respiratory distress syndrome. Zhongguo Dang Dai Er Ke Za Zhi 11: 771-772, 2009 (In Chinese).

12. Wu X, Li S, Zhang J, Zhang Y, Han L, Deng Q and Wan X Meta-analysis of high doses of ambroxol treatment for acute lung injury/acute respiratory distress syndrome based on randomized controlled trials. J Clin Pharmacol 54: 1199-1206, 2014.

13. Ketko AK and Donn SM: Surfactant-associated proteins: Structure, function and clinical implications. Curr Pediatr Rev 10: 162-167, 2014

14. Gortner L, Schüller SS and Herting E: Review demonstrates that less invasive surfactant administration in preterm neonates leads to fewer complications. Acta Paediatr 107: 736-743, 2018.
15. Zhang $\mathrm{C}$ and Zhu X: Clinical effects of pulmonary surfactant in combination with nasal continuous positive airway pressure therapy on neonatal respiratory distress syndrome. Pak J Med Sci 33: 621-625, 2017.

16. Baranwal AK, Murthy AS and Singhi SC: High-dose oral ambroxol for early treatment of pulmonary acute respiratory distress syndrome: An exploratory, randomized, controlled pilot trial. J Trop Pediatr 61: 339-350, 2015.

17. Gonzalez Garay AG, Reveiz L, Velasco Hidalgo L and Solis Galicia C: Ambroxol for women at risk of preterm birth for preventing neonatal respiratory distress syndrome. Cochrane Database Syst Rev (10): CD009708, 2014.

18. Zhang ZQ, Huang XM and Lu H: Ambroxol for the prevention of respiratory distress syndrome in preterm infants: A meta analysis. Zhongguo Dang Dai Er Ke Za Zhi 12: 858-863, 2010 (In Chinese).

19. Elsayed HF, Elkhaiouby MI, Elsharkawey SM and Elnemr MA: Evaluation of the role of postnatal ambroxol in the prevention and treatment of respiratory distress syndrome in preterm neonates. Sultan Qaboos Univ Med J 6: 41-46, 2006.

20. Carrera G, Liberatore A, Riboni G and Clementi M: Surfactant and ambroxol in the therapy of idiopathic respiratory syndrome in newborn infants. Minerva Pediatr 43: 723-730, 1991 (In Italian).

21. Marini A, Franzetti M, Gios G, Flauto U, Arosio A, Maccabruni M, Rondini G, Chirico G, Giancola A, Console V, et al: Ambroxol in the treatment of idiopathic respiratory distress syndrome. An interim report on a controlled double-blind multicenter study versus placebo. Respiration 51 (Suppl 1): 60-67, 1987. 